\title{
Diversifying crop rotation improves system robustness
}

\author{
Junxian $\mathrm{Li}^{1,2} \cdot$ Lidong Huang ${ }^{3}$. Jun Zhang ${ }^{4}$ - Jeffrey A. Coulter ${ }^{5}$. Lingling $\mathrm{Li}^{1} \cdot$ Yantai Gan $^{2}$ (C)
}

Accepted: 30 May 2019 / Published online: 25 June 2019

(C) INRA and Springer-Verlag France SAS, part of Springer Nature 2019

\begin{abstract}
Agriculture requires a synergetic improvement in production profitability, long-term viability, and environmental health in the presence of abiotic (i.e., uncontrollable weather, input costs, and product prices) and biotic (i.e., weed pressure and disease infestation) stresses. A "robust" agroecosystem can enhance synergetic improvements by alleviating these stresses, but it is unknown how system robustness can be achieved in a systemic manner. Here, for the first time, we demonstrate that crop diversification can significantly enhance system robustness. An 8-year crop rotation study was conducted, in which 3-year crop sequences were repeated for two cycles, with the first cycle from 2010 to 2012 and the second from 2014 to 2016; each cycle began with a wheat (Triticum aestivum L.) crop, and pea (Pisum sativum L.), lentil (Lens culinaris Medik.), and mustard (Brassica juncea L.) were included in the rotation, and chickpea (Cicer arietinum L.), a $\mathrm{N}_{2}$-fixing legume susceptible to weed pressure and the foliar disease Ascochyta blight, was the last crop in each of the two cycles. Crop diversification improved system resistance to biotic stresses, and that chickpea in the diversified lentil-wheat-chickpea system had the lowest weed biomass and foliar disease severity among rotation systems. Chickpea in the diversified pea-mustard-chickpea system recovered from severe weed pressure by the end of the second cycle in 2016. Diversified systems increased resistance and resilience from abiotic stresses and improved the constancy in crop productivity across rotation cycles, compared to the less diversified systems. Quantitative assessments show that the most diversified systems had a $14 \%$ advantage in system robustness. We conclude that diversifying crop rotation improves system robustness through enhancing crop resistance to and resilience from biotic-induc ed disturbances and increasing the constancy of crop productivity while facing disturbance.
\end{abstract}

Keywords Abiotic stress $\cdot$ Crop rotation $\cdot$ Diversification $\cdot$ System resilience $\cdot$ Sustainability $\cdot$ Perturbation

\section{Introduction}

Agriculture is facing significant challenges with changing climate (Smirnov et al. 2016), unpredictable weather (Stott 2016), and biotic stresses (Tao et al. 2011; Liu et al. 2010). These perturbations often occur irregularly and unpredictably, and in many cases are inevitable (Farhangfar et al. 2015). The combination of climate-induced abiotic stresses with biotic stresses can dramatically decrease agroecosystem productivity (Mondal et al. 2016), profitability (Lin et al. 2008), and longterm sustainability (Lin et al. 2008; Tao et al. 2011). Application of pesticides, an approach commonly used for

\author{
Lingling Li \\ lill@gsau.edu.cn \\ Yantai Gan \\ yantai.gan@canada.ca \\ Junxian Li \\ junxian.li@outlook.com \\ Lidong Huang \\ ldhuangnz@163.com \\ Jun Zhang \\ zhangjun@imau.edu.cn \\ Jeffrey A. Coulter \\ jeffcoulter@umn.edu
}

1 Gansu Provincial Key Lab of Arid Land Crop Science/College of Agronomy, Gansu Agricultural University, Lanzhou 730070, Gansu, China

2 Agriculture and Agri-Food Canada, Swift Current Research and Development Centre, Swift Current, Saskatchewan S9H 3X2, Canada

3 Department of Agriculture Resources and Environment, Nanjing University of Information Science and Technology, Nanjing 210044 , China

4 College of Science, Inner Mongolia Agricultural University, Hohhot 010018, Inner Mongolia, China

5 Department of Agronomy and Plant Genetics, University of Minnesota, St. Paul, MN 55108, USA 
pest control to alleviate biotic pressures in conventional agroecosystems, carries large risks of environmental degradation and ecological disruption (Lin 2011; Vallina and Le Quéré 2011). Sustainable agriculture requires a synergetic improvement in crop productivity, environmental health, and ecological sustainability (Ifejika Speranza et al. 2014). These multiple objectives may be achieved through the development of a "robust" system (Ifejika Speranza et al. 2014) that combats various disturbances (Reckling et al. 2016) (Fig. 1). A robust cropping system is expected to be productive, profitable, and sustainable across a wide range of perturbations (Urruty et al. 2016).

"Robustness" originates from the Latin word robustus, meaning a strong resistance to vulnerability (de Goede et al. 2013; Asbjornslett 1999). The concept of robustness was initially used in statistics to describe methods that are not affected by small deviations, and it has since been widely used in economics (Lu and White 2014) and systems engineering (Ross et al. 2008). Recently, the concept of robustness has been adopted in ecological research to describe the ability of a system to cope with unexpected disturbances and uncertainty while maintaining the system's functionality (de Goede et al. 2013; Napel et al. 2006) and productivity (Urruty et al. 2016; de Goede et al. 2013; Sabatier et al. 2013). In the present study, the term "robust agriculture" is used to emphasize the ability to maintain a desired level of agricultural outputs in the presence of disturbance (Fig. 1). Improving a system's robustness requires systemic integration of multiple factors that affect plant growth, crop yield, and economic outcome. The "robustness" of an agricultural system is related to three metrics: (i) resistance, (ii) resilience, and (iii) constancy (Urruty et al. 2016; de Goede et al. 2013). Resistance is the ability of a system to remain essentially unchanged when subjected to disturbance, and its inverse is sensitivity and defenselessness (Harrison 1979; Allison 2004; Mondal et al. 2016). Resilience, since first introduced by an ecologist (C.S. Holling) in the 1970s, has been used to describe the capacity of a system to absorb disturbance and recover quickly once a disturbance is removed (Holling 1973; Pimm 1984; Harrison 1979). Constancy emphasizes a system's continuity of performance for high outputs and ecosystem services across different environmental conditions (de Goede et al. 2013; Urruty et al. 2016). These metrics may function independently or interact each other, affecting the outcome of the robustness of the system. For example, a higher crop plant density can increase the crop community's ability to compete with accompanying weeds, thereby increasing the system's resilience, but plants grown at higher density often have a greater severity of plant diseases, leading to reduced resistance of the system to biotic stresses. Therefore, it is important to coordinate the functions of these metrics in agricultural systems.

A diversified agroecosystem is considered theoretically robust in the presence of perturbations (Elmqvist et al. 2003; Kremen and Miles 2012). Many agronomic studies have focused on understanding how agronomic management practices improve crop productivity through suppressing pests

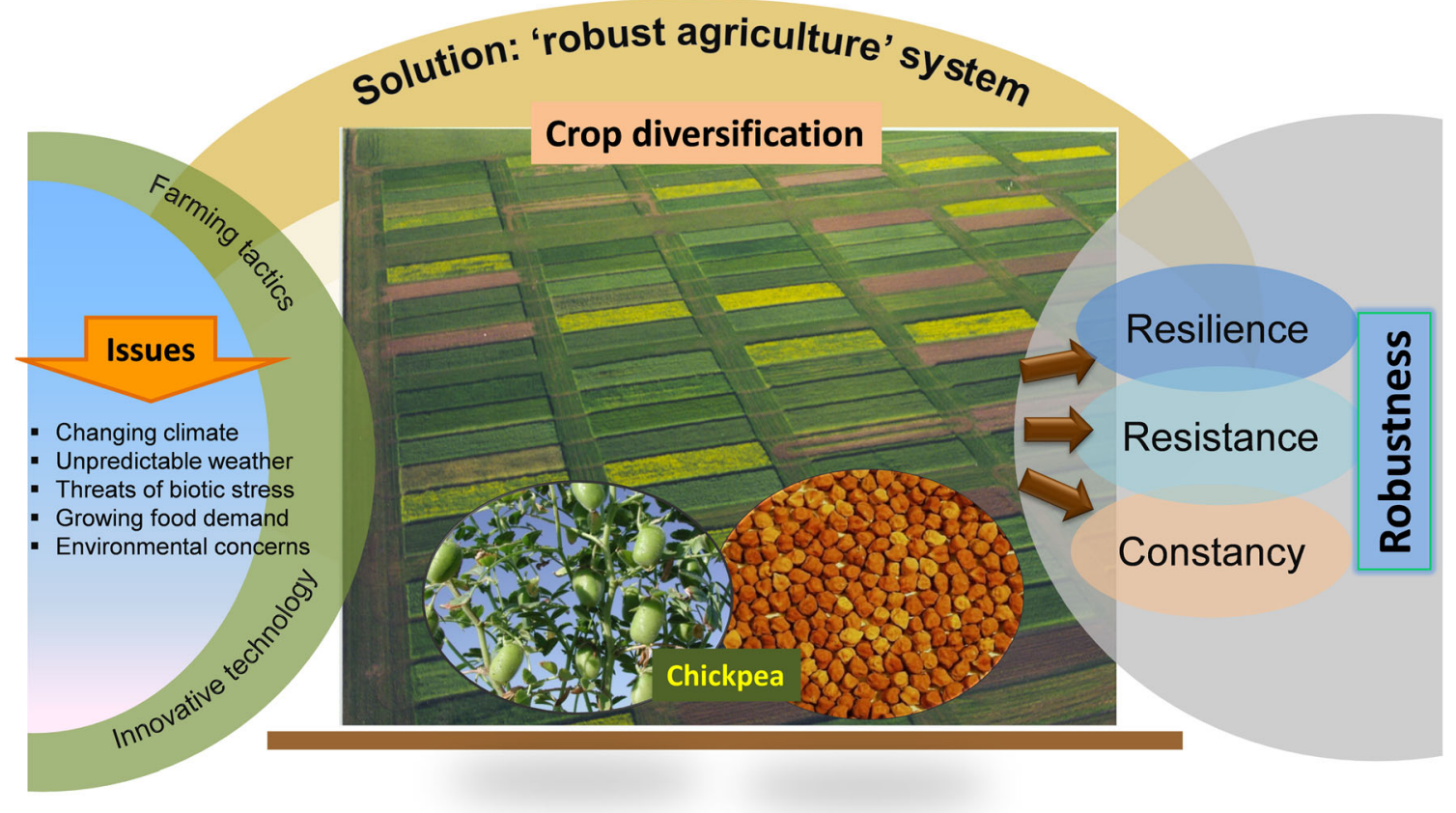

Fig. 1 A schematic illustration showing that a "robust agriculture" system can help alleviate the major issues and challenges in agriculture. Chickpea is used as an example to demonstrate that a robust agricultural system can be developed through resilience (from various perturbations), resistance to biotic stresses, and constancy in crop yield and profitability across disturbances 
(Gurr et al. 2003), avoiding pathogen infection (Zhu et al. 2000), reducing weed pressure (Kathiresan 2007), and buffering unusual climate variability (Lin et al. 2008; Lin 2011). However, these endeavors have often focused on relationships between specific factors and crop performance from a sole perspective and have lacked systemic consideration, which has a limited outcome. Cropping systems research that moves beyond single- or few factor treatments to assess system-level performance present a real-world approach, since farm managers rarely change only one factor at a time when making changes to cropping systems. Further, changing multiple factors at once can have a synergistic effect and produce a greater improvement in crop performance than if only one factor is changed (Coulter et al. 2011). Thus, a systemic conceptual framework is needed to develop robust agriculture systems to cope with various perturbations (Lin 2011). However, in the scientific literature, there are limited reports assessing system robustness with multi-crop rotations (de Goede et al. 2013; Urruty et al. 2016). Research is critically needed to better understand how adding diversity to cropping systems can enhance system robustness. The priority in evaluation of system robustness should be resistance, resilience, and constancy (de Goede et al. 2013; Napel et al. 2006).

Chickpea (Cicer arietinum L.) is a major legume crop worldwide. It has the ability to convert $\mathrm{N}_{2}$ from the atmosphere to inorganic $\mathrm{N}$ forms for crop production (Hossain et al. 2016), and is drought tolerant and thus suitable for production in arid and semiarid areas (Leport et al. 1999). However, this crop has many drawbacks: it is vulnerable to abiotic stresses such as a dry seedbed (Ganjeali et al. 2011) and excessive moisture during reproductive stages, which delays pod maturity (Navas-Cortés et al. 1998); it often suffers from weak competitiveness with accompanying weeds due to short plant height; it is vulnerable to injury from foliar-applied pesticides (Paolini et al. 2006), and it is susceptible to Ascochyta blight, a disease caused by Ascochyta rabiei, which can lead to yield losses $>90 \%$ under extreme circumstances (Gan et al. 2006). These obstacles present significant risks to chickpea production. Simultaneously, infected chickpea residue left on the soil surface is a potential host of diseases that can affect the performance of subsequent crops. Therefore, optimized chickpea growth and productivity is a prerequisite for a robust crop rotation system. In this study, we conducted two cycles of replicated rotations using the stress-vulnerable test crop-chickpea to determine whether system robustness could be enhanced by diversified crop rotations. The core indicators of robustness were (i) minimized damage to crop growth resulting from stresses such as weed pressure and disease infestation, (ii) maintenance of high plant nodulation for fixation of atmospheric $\mathrm{N}_{2}$ in the presence of disturbance, and (iii) improvement of crop yield and economic net return of the entire rotation system. If a robust system is successfully established that alleviates the challenges to chickpea production, the methodology developed in this study can be potentially extended to develop robust production systems for other crops.

The objective of this study was to determine whether diversified crop rotations improve system robustness by (i) determining resistance to, or resilience from these common stresses in chickpea, (ii) evaluating the constancy of plant nodulation and crop yields across two crop rotation cycles, and (iii) assessing system performance during the entire rotation length. We hypothesize that diversified rotation systems are more robust due to improved resistance to or resilience from stresses, leading to increased crop productivity and economic net return, relative to less-diversified rotation systems.

\section{Materials and methods}

\subsection{Experimental site}

A field experiment was conducted at the Agriculture and AgriFood Canada Swift Current Research and Development Centre $\left(50^{\circ} 25^{\prime} \mathrm{N}, 107^{\circ} 44^{\prime} \mathrm{W}\right)$ from 2010 to 2016 . The experimental site is typically droughty, with rainfall occurring mostly in July through September when chickpea is branching and flowering. It is windy during harvesting in autumn at this site, which often leads to crop seeds shattering and contributing to the weed seed bank. The soil was an Orthic Brown Chernozem. At the beginning of the experiment in the spring of 2009 , the soil contained $20 \mathrm{~g} \mathrm{~kg}^{-1}$ of organic $\mathrm{C}$ measured using automated combustion (Carlo Erba, Milan, Italy) (Gan et al. 2014), $35 \mathrm{mg} \mathrm{kg}^{-1}$ of Olsen $P$ measured using the Olsen method (Olsen and Sommers 1982), $266 \mathrm{mg} \mathrm{kg}^{-1}$ of exchangeable $\mathrm{K}$ measured using the ammonium-acetate method (Malhi et al. 2003), and a $\mathrm{pH}\left(0.01 \mathrm{~mol} \cdot \mathrm{L}^{-1} \mathrm{CaCl}_{2}\right.$ solution) of 6.5 measured using an electronic pH meter (PHB-600R, OMEGA Engineering, Canada) (Gan et al. 2015). Chickpea suffered from drought and cool weather in 2012, while in 2016 the crop received above-normal rainfall. Rainfall during the growing season (April to October) in 2012 (276 mm) was close to 30-year average $(284 \mathrm{~mm})$, while that in 2016 (496 $\mathrm{mm}$ ) was 1.7-fold greater than the 30-year mean. Accumulated growing degree days (GDD, $5.0{ }^{\circ} \mathrm{C}$ base air temperature $)$ in $2012\left(673^{\circ} \mathrm{C}\right)$ was approximately half of that in $2016\left(1327^{\circ} \mathrm{C}\right)$.

\subsection{Experimental design}

The experiment included four 3-year crop sequences ending with chickpea as the test crop. Each rotation system was duplicated temporally for two cycles. The first cycle started in 2010 and ended in 2012, and the second cycle started in the original plots in 2014 and continued to 2016. The rotation systems included (i) diversified rotation systems, lentil- 
wheat-chickpea (LWC) and pea-mustard-chickpea (PMC); (ii) moderately diversified rotation systems, chickpeawheat-chickpea (CWC), and (iii) the least diversified rotation system, chickpea-chickpea-chickpea (CCC). The continuous chickpea arrangement in the first rotation cycle, chickpea (2010)-chickpea (2011)-chickpea (2012) (CCC), was modified to chickpea (2014)-mustard (2015)-chickpea (2016) (CMC) in the second cycle because of severe chickpea mortality in the CCC system which resulted in total crop failure in the third year of the rotation. Chickpea was selected as the dominant and test crop for the rotation systems since it is a typical vulnerable crop in the local area that can be severely impacted by weeds and diseases. Spring wheat was planted as a rotation break crop in 2009 prior to the first cycle and in 2013 prior to the second cycle. The first break crop of wheat in 2009 was excluded in the yield calculation because it affected all treatments equally. The second break crop of wheat in 2013 was to balance the soil condition; thus, chickpea yield in 2012 from the first cycle and 2016 from the second cycle were considered independent of each other. All crop sequences were arranged in a randomized complete block design with four replicates. Plots were $4 \times 12 \mathrm{~m}$, with all crops planted in rows spaced $0.15 \mathrm{~m}$ apart. There was a 4-m wide buffer area between plots and a 16-m wide pathway between replicates to avoid interference between treatments and provide space for field operations. Barley (Hordeum vulgare L.) was grown in the buffer area and was mowed regularly to avoid weed occurrence. The cultivars used in the experiment were Brigade for wheat, CDC Meadow for pea, CDC Frontier for chickpea, CDC Maxim CL for lentil, and Cutlass for mustard (Saskatchewan Crop Insurance Corporation, Canada), and were widely grown in the local production area at the time of the experiment.

\subsection{Crop management}

All plots were directly seeded into standing wheat stubble using a no-till drill. Pulse seeds were inoculated with effective Rhizobium inoculant at the time of seeding (Gan et al. 2015). The seeding rate for each crop was determined based on the rate of seed germination, and the expected rate of emergence in the field to target an optimal plant population. Chickpea, wheat, pea, lentil, and mustard were seeded at 564,900, 2,910,000,1,000,000, 1,500,000, and $1,880,000$ seeds $\mathrm{ha}^{-1}$. Herbicides, insecticides, and fungicides were applied to plots according to recommendations from the local government. A combination of the fertilizers 46-0-0 (N- $\left.\mathrm{P}_{2} \mathrm{O}_{5}-\mathrm{K}_{2} \mathrm{O}\right)$ and 11-51-0 $\left(\mathrm{N}-\mathrm{P}_{2} \mathrm{O}_{5}-\mathrm{K}_{2} \mathrm{O}\right)$ was broadcast annually at seeding to supply $54.9 \mathrm{~kg} \mathrm{~N} \mathrm{ha}^{-1}$ for wheat and mustard, $4.7 \mathrm{~kg} \mathrm{~N} \mathrm{ha}^{-1}$ for lentil, pea, and chickpea, and $21.9 \mathrm{~kg} \mathrm{P}_{2} \mathrm{O}_{5} \mathrm{ha}^{-1}$ for all crops in each year. At full maturity, an area of $14.4 \mathrm{~m}^{2}(1.2 \times 12 \mathrm{~m})$ of crop rows was harvested in the central portion of each plot using a plot combine. Harvested grain was air-dried, cleaned, and weighed to determine grain yield. Crop residues were retained on the soil surface.

\subsection{Data collection and calculation}

The incidence of Ascochyta blight in chickpea was measured in 2012 and 2016 at late flowering in each plot using the Horsfall-Barratt scale (Gan et al. 2006). Weed biomass was measured at the flowering stage of chickpea. An area of $0.5 \mathrm{~m}^{2}$ was sampled within the central part of each plot, and weeds were separated from chickpea plants, dried in a forced-air oven at $60{ }^{\circ} \mathrm{C}$ until constant mass, and weighed. Nodules of chickpea plants were measured in 2012 and 2016 at the midflowering stage when the plants have maximum nodulation (Gan and Liang 2010). Ten plant-root-soil matrixes were excavated from the 0 - to $50-\mathrm{cm}$ soil depth in each plot and the aboveground plant parts were removed. After initial soil removal in the field, the roots were carefully placed in unsealed plastic bags with tap water and soaked overnight at $4{ }^{\circ} \mathrm{C}$. On the following day, rhizosphere soil was removed from the roots, leaving nodules retained on the roots. The total number of nodules was counted from 10 plants and those nodules with an internal pink color were considered effective $\mathrm{N}_{2}$-fixing nodules. All nodules from the 10 plants were bulked and oven-dried at $60{ }^{\circ} \mathrm{C}$ in a forced-air oven until constant mass and weighed.

To enable comparison between years and among rotation systems with different crops, relative nodulation and yield of crops were calculated using the following equations (Fuentes et al. 2009):

$$
\begin{aligned}
& R N C(\%)=I N S T / M N A T \times 100 \% \\
& R Y C(\%)=I Y S T / M Y A T \times 100 \% \\
& R Y A C(\%)=S R Y A C / N C \times 100 \%
\end{aligned}
$$

In Eq. 1, RNC, INST, and MNAT represent the relative nodulation of chickpea, the individual nodulation of chickpea in a specific treatment and replication, and the mean nodulation of chickpea grown in all treatments within a given replication. In Eq. 2, RYC, IYST, and MYAT represent the relative yield of chickpea, the individual yield of chickpea in a specific treatment and replication, and the mean yield of chickpea grown in all treatments within a given replication. In Eq. 3, $R Y A C, S R Y A C$, and $N C$ represent the relative yield of all crops in an entire rotation sequence for a given rotation cycle and replication, the sum of relative yield of all crops for a given rotation cycle and replication, and the number of crops in rotation.

Based on the objectives and methods in this experiment, robustness was assessed using the methods presented by de Goede et al. (2013), which are summarized below. Robustness 
consisted of three components - resistance, resilience, and constancy, and was quantified using the key agronomic indicators evaluated in this study. Resistance was indicated by the degree of scarcity of biotic and abiotic stresses, namely, weed and disease pressure. Resilience was indicated by the degree of crop recovery from these disturbances in the second rotation cycle compared to the first, with the assumption that disturbance, if any, was minor at the initial stage of the first cycle. Constancy was the degree to which productivity-related variables were maintained constantly across the two rotational cycles. Using crop yield as an example, the "constancy" of chickpea yield was assessed as the difference between the mean "relative" yield in two rotation cycles and the mean relative value of mean of chickpea yields in all treatments in all treatments across both rotation cycles. The same method was applied to determine constancy in nodulation and economic return. Resistance was calculated using following equations:

$$
\begin{aligned}
R S_{\mathrm{W}}(\%) & =100 \%-R B_{\mathrm{w}} \\
R S_{\mathrm{d}}(\%)= & 100 \%-D I \\
\operatorname{TRS}(\%)= & \left(R S_{w} \times R H_{w}\right)_{2012}+\left(R S_{d} \times R H_{d}\right)_{2012} \\
& \left.+\left(R S_{w} \times R H_{w}\right)_{2016}+\left(R S_{d} \times R H_{d}\right)_{2016}\right) / 2
\end{aligned}
$$

In Eq. $4, R S_{\mathrm{w}}$ and $R B_{\mathrm{w}}$ represent resistance to weed pressure and relative weed biomass in each year for a given replication, respectively. In Eq. 5, $R S_{\mathrm{d}}$ and $D I$ represent resistance to Ascochyta blight and the incidence of Ascochyta blight in each year for a given replication, respectively. In Eq. 6, TRS represents total resistance of a rotation system to weed pressure and Ascochyta blight for a given replication; $R S_{\mathrm{w}, \mathrm{d}}$ represents individual resistance to weed pressure and Ascochyta blight for a given replication; and $R H_{\mathrm{w}, \mathrm{d}}$ represents the relative harmfulness of weed pressure and Ascochyta blight for a given replication. The relative harmfulness of weed pressure and Ascochyta blight was calculated according to dominance analysis (Azen and Budescu 2003). Resilience of a rotation system was calculated using following equations:

$$
\begin{aligned}
& \operatorname{TRH}(\%)=R B_{w} \times R H_{w}+D I \times R H_{d} \\
& T R L(\%)=T R H_{2012}-T R H_{2016}
\end{aligned}
$$

In Eq. 7, TRH represents the total harmfulness of weed pressure and Ascochyta incidence in each year for a given replication; $R B_{\mathrm{w}}$ and $D I$ represent the relative biomass of weeds and incidence of Ascochyta blight for a given replication, respectively, and $R H_{\mathrm{w}}$ and $R H_{\mathrm{d}}$ represent the relative harmfulness of weed pressure and foliar disease for a given replication, respectively. In Eq. 8, TRL represents the total resilience of a rotation system from weed pressure and Ascochyta blight in 2016 relative to 2012 for a given replication. Constancy was calculated using following equations:

$C Y(\%)=M R Y-100 \%$

$C N(\%)=M R N-100 \%$

$C Y A(\%)=R Y A-100 \%$

$C R A(\%)=R R A-100 \%$

In Eq. 9, $C Y$ and $M R Y$ represent the constancy of chickpea yield and the mean relative chickpea yield in 2 years for a given replication, respectively. In Eq. 10, $C N$ and $M R N$ represent the constancy of chickpea nodulation and mean relative nodulation produced in 2 years for a given replication, respectively. In Eq. 11, CYA and RYA represent the constancy of total yield of all crops and the relative yield of all crops in the entire rotation length for a given replication, respectively. In Eq. 12, $C R A$ and $R R A$ represent the constancy of total net return of all crops and the relative return of all crops harvested in the entire rotation length for a given replication, respectively. Seed yield and nodulation of chickpea, and total productivity and net return of the entire rotation length were considered equally import in this study. Among the three metrics (resistance, resilience, and constancy) that constitute system robustness, constancy of productivity is the ultimate goal in crop rotation, while resistance and resilience contribute to the performance of constancy. Therefore, constancy was given more weight than resistance and resilience. Here, we calculated system constancy using chickpea yield, nodulation, total yield of the entire rotation, and net income across two rotation cycles. Each of the four production-related variables was given equal weight as contributing factors. Therefore, the total robustness was calculated as:

$T R B(\%)=(T R S+T R L+C Y+C N+C Y A+C R A) / 6$

The thresholds of resistance, resilience, and constancy were from -100 to $100 \%$. We defined rotation systems with these parameters $>0$ as having robustness and those with the highest values as having the greatest robustness. A rotation with the sum of these parameters $<0$ represented a system with no robustness.

The economic outcome of growing a specific crop may affect a farm manager's decision on how and whether to include the crop within a rotation system. We determined economic outcome of a rotation system based on crop prices, yields, and costs of production for the different crops using the following equation:

$N R(U S A$ dollar,$)=T R-T C$

In Eq. 14, $N R, T R$, and $T C$ represent net return, total revenue, and total cost of production for all crops grown in the entire rotation length for a given replication, respectively. Crop prices and costs of production for each crop were 
obtained from the Government of Saskatchewan (Anonymous 2015). The total cost of crop production included fixed and variable costs. Fixed costs included land investment, property taxes, and machinery investment, whereas variable costs included fertilizers, chemicals (herbicides, insecticide, fungicides, and inoculant), labor costs for operation of machinery, crop insurance, utilities, and miscellaneous items.

Weather data were obtained from a weather station located about $300 \mathrm{~m}$ from the experimental site. Growing degree days (GDD) were calculated using the following equation (McMaster and Wilhelm 1997):

$$
G D D\left({ }^{\circ} C\right)=\sum\left(T_{m}-T_{b}\right)
$$

In Eq. 15, $T_{\mathrm{m}}$ and $T_{\mathrm{b}}$ represent the daily mean and base air temperatures, respectively. The base temperature was set to 5 ${ }^{\circ} \mathrm{C}$ (Blackshaw et al. 2011).

\subsection{Statistical analysis}

Yields of different crops were normalized to relative yield on a percentage basis to enable comparison among years and crops. The relative harmfulness of Ascochyta blight and weed pressure was normalized according to dominance analysis (Azen and Budescu 2003). Resistance, resilience, and constancy were normalized to a percentage basis to determine system robustness. All indices were measured from four replicates except for the root parameters, which were measured from three replicates. Data were subject to analysis of variance (ANOVA) using "Ime4" package in R statistical software (version 3.3.1). Fisher's protected least significant difference (LSD) test at $\alpha=0.05$ was used to compare means. Normality and homogeneity of variance was assessed prior to ANOVA using the Shapiro-Wilk and Barlett tests $(\alpha=$ 0.05) (Zhang et al. 2018).

Data availability The datasets generated during and/or analyzed during the current study are available from the corresponding authors on reasonable request.

\section{Results and discussion}

Sustainable agricultural development requires a synergetic improvement in profitability and sustainability in the presence of abiotic and biotic stresses. A robust cropping system can provide solutions to combat abiotic and biotic stresses. Through this 8-year crop rotation study with various cropping sequences in which chickpea, an annual legume vulnerable to stresses, was used as a test crop, we found that diversified cropping systems can improve system resistance to and resilience from biotic stresses, and thus enhance system robustness.

\subsection{Diversification improved system resistance to and resilience from biotic stresses}

As the two major metrics constituting system robustness, resistance to and resilience from stresses play an import role in crop production. With climate change, abiotic and biotic stresses affecting plant growth and crop performance are inevitable, unpredictable, and uncontrollable. It has been a challenge to describe these two metrics in a quantitative manner, but their biological means are now understood better than before. Many factors may affect the magnitude of these two metrics. For the chickpea-based system evaluated in the present study, resistance was largely based on the ability of chickpea to resist Ascochyta blight due to its high susceptibility to the pathogen, and the capacity of chickpea to tolerate weed pressure due to its short plant height and the weak competitiveness with accompanying weeds. Resilience was the capacity to respond to the combined effects of stressful weather conditions encountered during the growing season and disease and weed infestations. In other more complex ecological systems, resilience could be expressed with other terms, such as the ability to bounce back, rebound, or recover, and tenacity, ductility, and plasticity (Holling 1973; Pimm 1984; Harrison 1979). However, a complex assessment of resilience may lose the focus or even produce misleading information. We suggest that resilience in crop production focus on the assessment of system recovery from a disturbed state for a lower level of productivity loss across temporal rotational cycles.

In the present study, chickpea plants in all rotations were infected by Ascochyta blight, a foliar disease caused by Ascochyta rabiei and also suffered from high weed pressure in both rotation cycles (Fig. 2a, b). Chickpea plant debris serves as an overwintering host for Ascochyta rabiei, which can affect the same crop in subsequent years. Additionally, high infestations of weeds contribute to a high weed seedbank that can affect subsequent crops and rotation systems including chickpea are highly vulnerable to biotic stresses. Thus, in crop rotations with chickpea, optimization of chickpea production is a crucial precondition for enhancing robustness of the entire rotation system, and the key is to improve resistance to stresses from weeds and diseases.

Using relative importance dominant analysis (Azen and Budescu 2003), we quantified the magnitude of the key stresses that affected system robustness and found that the relative harmfulness of Asochyta blight and weed pressure to system robustness was 53 and 47\% in 2012, and 69 and 31\% in 2016, respectively. Overall, this disease contributed to the reduction of system robustness more than weed pressure.

The pattern of crop rotation had a significant impact on the magnitude of Ascochyta blight in both cycle-years (Fig. 2a). Chickpea in the monoculture CCC system was most seriously infected in 2012 and in subsequent CMC in 2016. Chickpea in the CWC system was less infected by Ascochyta blight than 


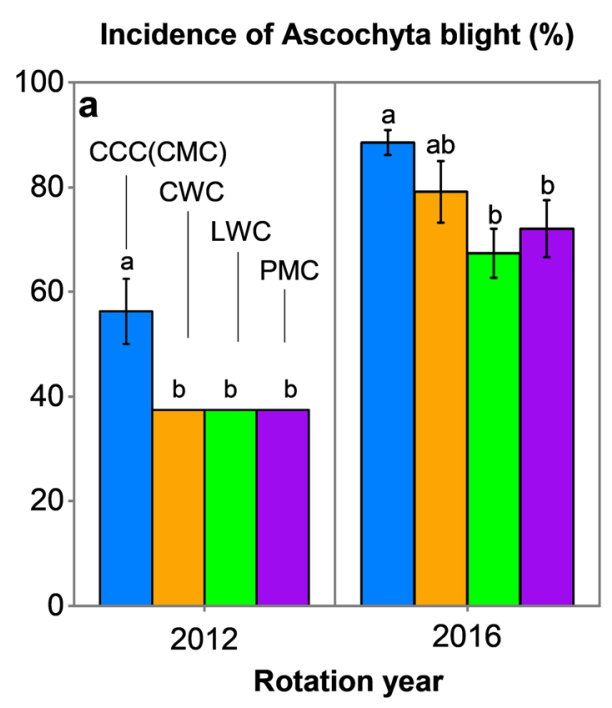

Fig. 2 Foliar disease and weed pressure in different rotation systems. a Incidence of foliar disease Ascochyta blight of year-3 chickpea and $\mathbf{b}$ the dynamic change of weed biomass in the different rotation systems from 2010 to 2016. The 3-year rotations were run for two cycles; the first cycle started in 2010 and completed in 2012, and the second cycle started in 2014 and completed in 2016. In both cycles, each rotation system had the year-3 crop chickpea as the test crop (i.e., chickpea in 2012 in the first

CCC in 2012, but both systems had severe incidence of the foliar disease by the end of the second cycle in 2016. In 2012, incidence of Ascochyta blight in the diversified LWC system was about 50\% less than that in the monoculture CCC system; in 2016, incidence in the LWC system was $21 \%$ less than that in the $\mathrm{CMC}$ system. Across the two rotation cycles, the diversified LWC system had significantly greater resistance to Ascochyta blight than the least diversified CCC and CMC systems, and no resilience to an improved level was exhibited across two cycles for the CCC-CMC system.

Higher severity of Ascochyta blight in 2016 than in 2012 was associated with excessive rainfall during the branching and flowering stages, as precipitation is a key factor triggering Ascochyta infection (Leport et al. 1999). Higher incidence of Ascochyta blight at the end of the second cycle in 2016 compared to at the end of the first cycle in 2012 was most likely due to the buildup of Ascochyta blight inoculum on chickpea residue throughout the two rotation cycles. The pathogen for this disease can overwinter on the chickpea debris and affect the same host crop in subsequent years when conditions are favorable (Gossen and Miller 2004; Gan et al. 2006).

The more diversified LWC and CWC systems were more resistant to weed pressure than the least diversified CCCCMC system (Fig. 2b). In 2012, chickpea in the diversified PMC system suffered from volunteer mustard (Brassica juncea $\mathrm{L}$.) derived from the preceding mustard crop, whereas chickpea in the monoculture CCC system was disturbed by high weed pressure from the large weed seedbank derived from chickpea cropping during the previous 3 years. Accompanying weeds compete with crop plants for nutrients
Weed biomass (kg DM ha-1)

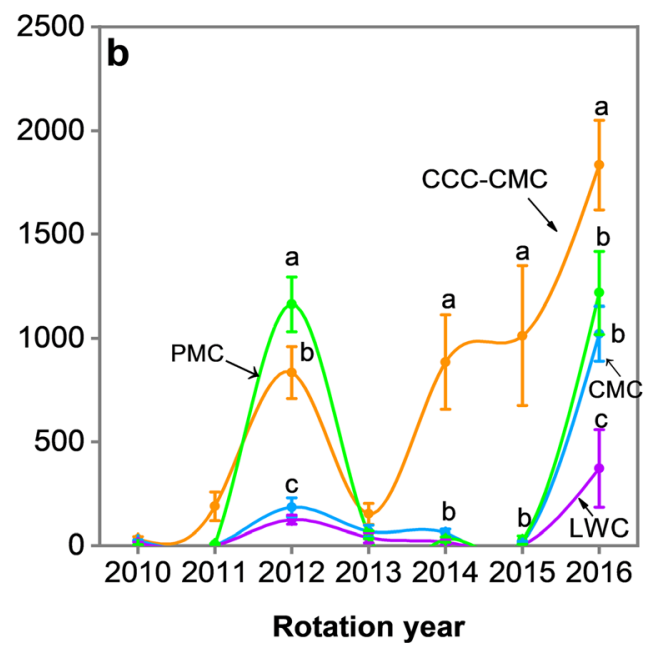

cycle and chickpea in 2016 in the second cycle). Wheat was grown in 2009 as a soil balance crop and then in 2013 as a rotation-breaking cereal. The rotational sequences were designed using chickpea $(\mathrm{C})$, wheat $(\mathrm{W})$, lentil (L), pea (P), and mustard (M). The rotation system CCC in the first cycle was modified to $\mathrm{CMC}$ in the second cycle due to severe disease pressure on continuous chickpea. Values are expressed as mean \pm standard error

and growth space (Koocheki et al. 2009; Nichols et al. 2015). Higher resistance to weed pressure in the more diversified LWC and CWC systems was probably associated with the previous "rotation break" wheat crop in 2011, because wheat straw may have provided some allelopathic potential to reduce weed pressure in the subsequent year (Koocheki et al. 2009; Benech-Arnold et al. 2000). The allelopathic effect can cause weed seeds to remain in dormancy immediately following wheat, but many of these weed seeds can emerge in chickpea since chickpea is a weak competitor with weeds (Smith et al. 2011). Some weeds growing in a chickpea community can increase the weed seedbank or rhizomes in the soil, thereby having a residual effect on subsequent crops (Benech-Arnold et al. 2000; Cici et al. 2008). The inclusion of a wheat break crop in 2013 reduced weed density in all plots. From 2014 to 2016, weed biomass in the diversified LWC and PMC systems and the less-intensified CWC system was significantly less than that in the chickpea-intensified CCC-CMC system, indicating greater resistance in these rotation systems (Fig. 2b). In 2016, weed biomass in the least diversified CMC system was 3.9-fold greater than that in the LWC system, $51 \%$ greater than that in the PMC system, and 79\% greater than that in the CWC system. The least diversified CCC-CMC system had the lowest resistance in 2016, suggesting the weakest resilience to weed-associated stresses.

The least diversified CCC system and most diversified PMC system suffered from severe weed pressure at the end of the first cycle in 2012; this disturbance in the CCC system was ongoing at the end of the second cycle in 2016 despite adjusting chickpea to mustard in 2015 (Fig. 2b). In contrast, 
chickpea in the diversified PMC system recovered from the serious weed pressure at the end of the rotation in 2016. The diversified LWC system was least disturbed by weed pressure. These findings reveal that chickpea in the diversified PMC and LWC systems had greater resistance to or resilience from weed pressure, while chickpea in the less diversified CCC system exhibited the least resistance to weed stress. To improve the resistance and resilience for the CCC system, greater frequency of crops other than chickpea is needed. These results show that crop diversification can be used to systematically improve system resistance to stresses from weeds and diseases, supporting the hypotheses of other researchers (Paolini et al. 2006).

\subsection{Diversification promoted system constancy on chickpea yield and overall productivity}

The key outcome of system robustness is constancy. We assessed constancy of the rotation systems by determining whether a high level of performance (e.g., crop yield, nodulation, net return) was maintained across two rotation cycles. A system with high crop performance in first cycle, but not in the second cycle, indicates no constancy.

Chickpea in the diversified systems had greater buffering capacity by improving root nodulation and enhancing the "weathering capacity" against the negative effects of dry conditions and low GDDs on nodulation. Improved nodulation helped fix more $\mathrm{N}_{2}$ from the atmosphere to provide part of the $\mathrm{N}$ requirement for chickpea growth. In 2012 and 2016, chickpea in the diversified LWC and PMC systems had 5.0- and 2.5 -fold greater nodule biomass, respectively, than those in the $\mathrm{CCC}$ or CMC systems (Fig. 3a), indicating that the diversified LWC and PMC systems had greater constancy of nodule production across the two rotation cycles. Nodule biomass in
2016 in the modified CMC system was 2.6-fold greater than that in the initial CCC system in 2012, but it had least nodulation in 2016, suggesting no constancy of nodulation for the CCC-CMC system. The less intensified CWC system had high nodulation in 2012, but nodulation was reduced substantially by the end of the second cycle, indicating no constancy.

Chickpea seed yield differed substantially between study years, and the magnitude of the year effect varied with rotation system. Seed yield of chickpea in the diversified PMC and LWC systems was 100 and $98 \%$ greater than that in the CCC system in 2012 (Fig. 3b). Chickpea in the LWC system had greater seed yield than CWC and CCC (or CMC) systems in both 2012 and 2016. Chickpea in the PMC system recovered from serious weed pressure and achieved the highest yield in 2016; in contrast, chickpea yield in the CWC system was $20 \%$ less at the end of the second cycle compared with the first cycle. Overall, the diversified LWC system had significantly greater constancy of chickpea yield than the less diversified CCC-CMC and CWC systems.

Comparison of total yield of all crops in the entire rotation cycle provides an indication of overall crop productivity at the system level. To enable comparison of total yield of all crops, normalized relative yield was calculated for crops in the different rotation systems for each production year and each rotation cycle. The assessment of normalized relative yield provides an indication of the dynamic change of the system's resilience to the relevant stresses during the production year.

On average, relative yields of all crops in the LWC, $\mathrm{CWC}$, and PMC systems were significantly greater than that of $\mathrm{CCC}$ in the first cycle. By the second cycle, the LWC and PMC systems maintained higher yields, while the CWC system reduced yield significantly (Fig. 4a). The CCC-CMC system expressed the lowest relative yield in both rotation cycles. Across the two cycles, relative
Fig. 3 Nodulation and seed yield of the year-3 chickpea in different rotation systems. a Nodule biomass and $\mathbf{b}$ seed yield of year3 chickpea. The rotation names and error bars are described in Fig. 2

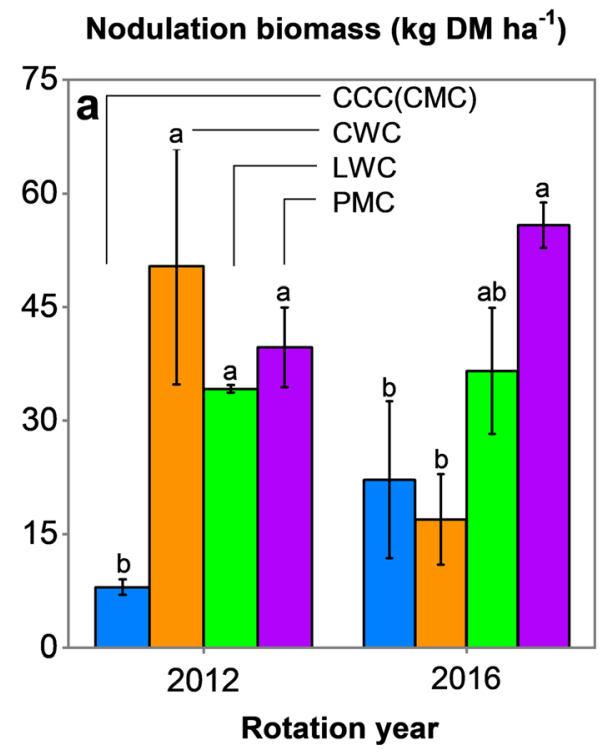

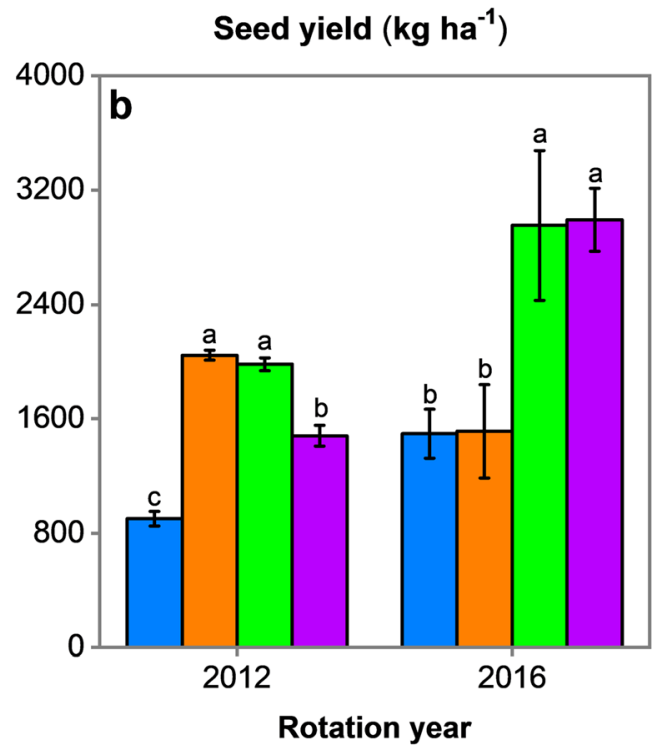


Fig. 4 Relative yield of all crops and the economic outcome in the different rotation systems. a Relative yield of all crops in a rotation cycle across the two rotation cycles and $\mathbf{b}$ net return in a rotation cycle in the different rotation systems. Relative yield in a was the average yield of all crops in the rotation. Net return in b was calculated using the Saskatchewan provincial government guidelines for costs and product prices (Anonymous 2015), and the values are in US dollars. The rotation names and error bars are described in Fig. 2

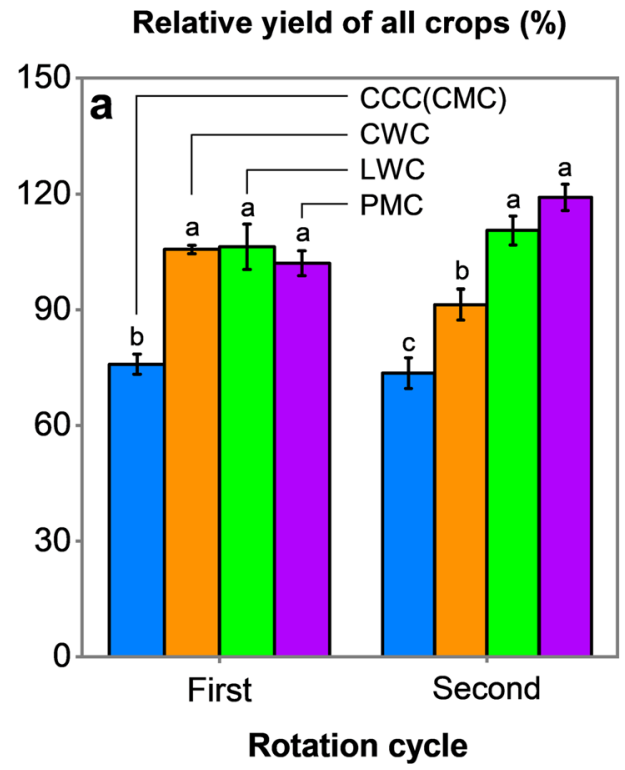

Relative yield of all crops (\%)

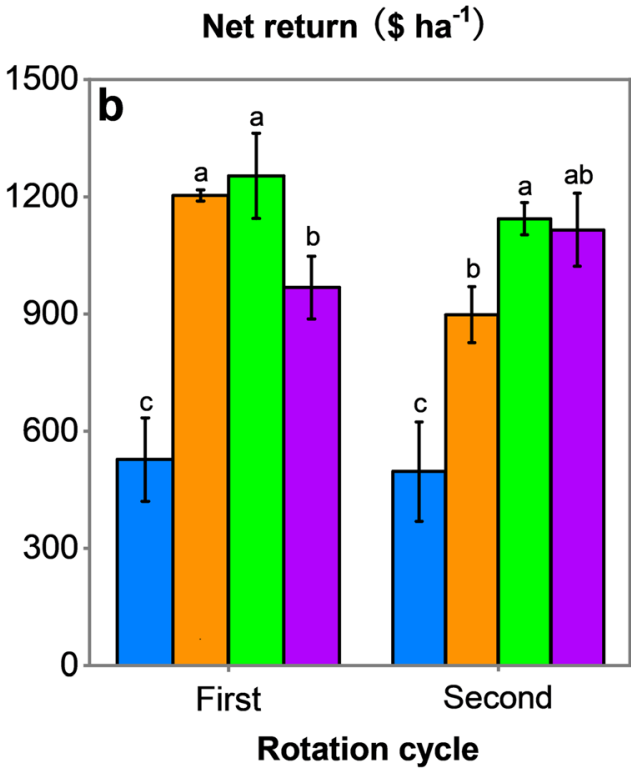

yield of the PMC, LWC, and CWC systems averaged 25\% greater compared to the least diversified system (CCC in the first and $\mathrm{CMC}$ in the second cycle).

Net return (gross revenue minus costs) with the CWC and LWC systems was significantly superior compared with CCC and PMC in first cycle, but CWC was unable to maintain the higher performance in the second cycle (Fig. 4b). Net return with the PMC system was intermediate compared to the other systems in the first cycle, and it increased significantly to a higher level relative to the other systems in the second cycle. The CCC-CMC system expressed the lowest net return in both cycles. Averaged across the two cycles, net return with the diversified PMC and LWC systems was double that of the CCC-CMC system (Fig. 4b).

The improvement of net return in the diversified PMC and LWC systems was associated with greater yield and a reduction in production costs (mainly $\mathrm{N}$ fertilizer and pesticides). These results coincide with those from previous studies showing that diversified rotation systems improve productivity and profitability (Davis et al. 2012; Gan et al. 2015; Liebman et al. 2013). Crop productivity is often influenced by weather conditions (Kumar et al. 2017). Increased system productivity with diversification in the present study was partly due to enhanced "weathering capacity" to abiotic stresses, an important means to cope with climatic conditions (Gan et al. 2006).

\subsection{Diversification enhanced system robustness}

Resistance, resilience, and constancy, the three metrics constituting system robustness, differed in how they affected the robustness of rotation systems across the two cycles (Fig. 5a). The LWC system experienced the greatest stresses in both cycles and the PMC system increased in resilience from the first to second cycles, while the CWC system did not maintain the superiority of productivity in the second cycle, although it had less foliar disease in the first cycle. Overall, the CCC and CMC systems had lowest resilience in both cycles, and the modification from CCC in the first cycle to CMC in the second cycle did not enhance resilience. Given the different magnitudes in which these three metrics affected system robustness, they were considered simultaneously in the calculation of system robustness. We quantified the degree of robustness using normalized percentages, with a higher value implying a greater robustness.

Chickpea in the diversified LWC system exhibited the greatest resistance to foliar disease and weed pressure, with $48 \%$ overall resistance in both rotation cycle-years (Fig. 5a). Chickpea in this system was less influenced by weed pressure and disease infestation; thus, less resilience was displayed. Chickpea in the PMC system recovered from high weed pressure experienced in the first cycle, contributing to the highest resilience from biotic stresses (44\%) including volunteer mustard from the previous year. During both rotation cycles, the two most diversified systems, LWC and PMC, maintained high constancy: 11 and 44\% for chickpea nodulation, 34 and $11 \%$ for chickpea seed yield, 5 and $8 \%$ for total yield for all crops in the entire rotation, and 23 and $12 \%$ for total net return. In contrast, no constancy occurred with the CCC-CMC and CWC systems, largely due to reduced nodulation and lowered crop yields. Consequently, the diversified LWC and PMC systems exhibited system robustness of 20 and $14 \%$, respectively, compared with negative values in the less diversified CCC-CMC and CWC systems. Increased system robustness with the diversified systems was attributable to the synergistic effect of increased resistance to and resilience from stresses, and enhanced constancies in nodulation and crop yield across the cycles (Fig. 5b). Diversifying crop rotations are reported to increase crop productivity (Kremen and Miles 2012, b) and 


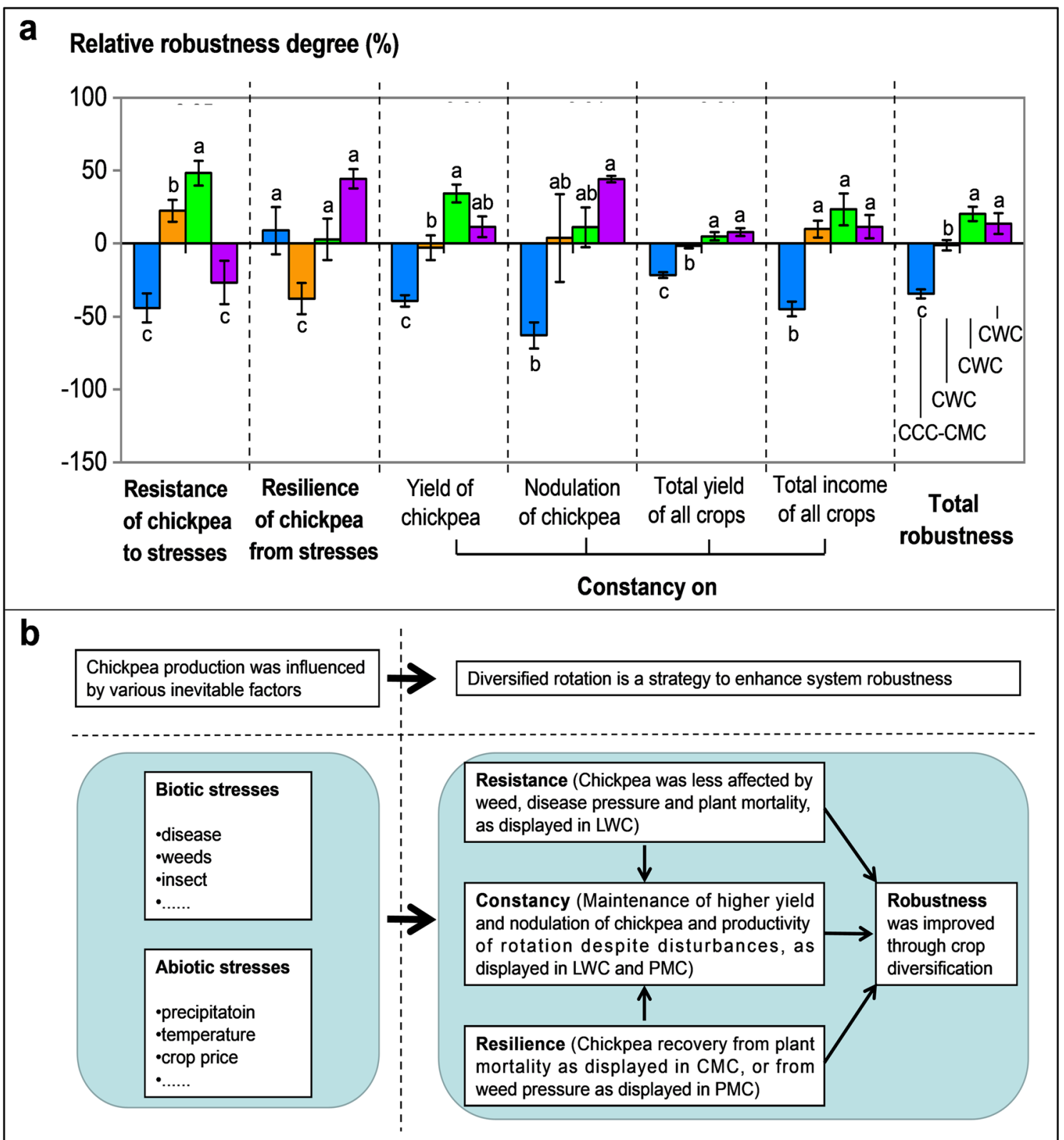

Fig. 5 Quantitative assessments and systemic diagram of robustness using the degree of resistance, resilience, and constancy in rotation from 2010 to 2016. a Quantitative assessments of systems robustness and b systematic diagram showing how diversifying crop rotation improved system robustness compared to the chickpea monoculture system (CCC). In panel a, robustness is comprised of three key components: (i) resistance, reflected on the scarcity degree of weed and disease pressures in chickpea when the crop faced biotic disturbances; (ii) resilience, exhibited after disturbances happened, showing the recovery from the disturbances in the second rotation cycle compared to the first; and (iii) constancy, emphasizing the ability to maintain plant nodulation, seed yield, total productivity, and net income across two rotation cycles. Systems robustness $(\%)=($ resistance + resilience + constancy of chickpea yield + constancy of chickpea nodulation + constancy of yield of all crops in the rotation cycle + constancy of net income of all crops in the rotation cycle) $/ 6$. The thresholds of resistance, resilience, and each constancy are from -100 to $100 \%$. A greater value indicates a more robust system and a negative value indicates the system had no robustness to biotic stresses. The rotation names and error bars are described in Fig. 2

Weather condition is one of the key abiotic factors influencing crop growth in the cool semi-arid northern Great Plains of North America (Gan et al. 2015). Temperature and precipitation also influence biotic stresses to crops (Lin 2011; Gaudin et al. 2015). The experimental site of this study typically experiences 
either drought or abundant precipitation during the branching and flowering stages of chickpea and is extremely windy during crop maturity, which often leads to seed shattering and harvest losses (Gan et al. 2009). The present study shows that crop diversification can be used as a means to minimize damage from these abiotic stresses by enhancing the robustness of chickpea-based rotation systems.

In the real world of agriculture, crops are inevitably influenced by various uncontrollable and unpredictable stresses, and to a certain extent the outcome of a production system depends on how the stresses are managed. The novel information generated from the present study suggests that a robust cropping system should be developed and adopted in farming. In research, focusing on the improvement of a system's robustness through the enhancement of the three metrics (resistance, resilience, and constancy) at the presence of disturbances should be considered a key objective. Each crop has unique characteristics and growth traits, and key agronomic indices that affect these metrics need to be measured to understand their linkage with system robustness. In practice, plant traits, agronomic indices, and system performance or robustness can be linked. It is encouraged that researchers interested in studying system robustness collect first-hand data from field performance and link them with resistance, resilience and constancy. Nevertheless, research on "system robustness" in crop production is still in its infant stage, and the findings from this study are among the first to show the power of system robustness. More sophisticated methodologies are needed to quantify the "robustness" in different cropping systems.

\section{Conclusion}

A robust cropping system can increase profitability and sustainability in crop production. The presence of abiotic and biotic stresses negatively affects the robustness of an agroecosystem. Using chickpea, a legume crop susceptible to Ascochyta blight disease and vulnerable to weed competition for growth resources, we demonstrate, from two cycles of chickpea-based rotations over 7 years, that diversifying crop rotation improves system robustness through (i) enhancing crop resistance to and resilience from biotic-induced disturbances, and (ii) increasing the constancy of crop yield and root nodulation of chickpea, total productivity of all crops in the entire rotation, and net return across two rotation cycles. The robustness established for this typical annual legume, chickpea, provides a foundation for a conceptual framework to establish robust agroecosystems for the production of other crops.
Acknowledgments We thank Lee Poppy, Ray Leshures, and Limin Luan for their valuable technical assistance with the field plot management and data collection, and Yining Niu, Jianling Fan, and Chen Gu for suggestions on data interpretation and presentation.

Author contributions YG initiated and designed the research; JL analyzed the data and wrote the manuscript with guidance from YG and $\mathrm{LL}$; LH, JZ, and JAC contributed to the data analysis and manuscript preparation; all authors reviewed and approved the paper; and YG finalized the paper.

Funding information This study was supported by the MOE-AAFC Ph.D. Research Program (Ministry of Education, China, and Agriculture and Agri-Food, Canada) that was financed by the National Natural Science Foundation of China (Rewards 31460337, 31660373, and 31761143004) and the Education Department of Gansu Province, China (Reward 2017C-12). The authors acknowledge the financial support of Saskatchwan Pulse Growers for conducting the field experiments.

\section{Compliance with ethical standards}

Conflict of interest The authors declare that they have no conflict of interest.

\section{References}

Allison G (2004) The influence of species diversity and stress intensity on community resistance and resilience. Ecol Monogr 74(1):117-134. https://doi.org/10.1890/02-0681

Anonymous (2015) Guide to crop protection. Government of Saskatchewan, Regina, Saskatchewan, Canada, pp. 554

Asbjornslett BE (1999) Assess the vulnerability of your production system. Prod Plan Control 10(3):219-229

Azen R, Budescu DV (2003) The dominance analysis approach for comparing predictors in multiple regression. Psychol Methods 8(2):129 148

Benech-Arnold RL, Sánchez RA, Forcella F, Kruk BC, Ghersa CM (2000) Environmental control of dormancy in weed seed banks in soil. Field Crop Res 67(2):105-122. https://doi.org/10.1016/S03784290(00)00087-3

Blackshaw R, Johnson E, Gan Y, May W, McAndrew D, Barthet V, McDonald T, Wispinski D (2011) Alternative oilseed crops for biodiesel feedstock on the Canadian prairies. Can J Plant Sci 91(5): 889-896. https://doi.org/10.4141/cjps2011-002

Cici SZH, Adkins S, Hanan J (2008) A canopy architectural model to study the competitive ability of chickpea with sowthistle. Ann Bot 101(9):1311-1318. https://doi.org/10.1093/aob/mcn040

Coulter JA, Sheaffer CC, Wyse DL, Haar MJ, Porter PM, Quiring SR, Klossner LD (2011) Agronomic performance of cropping systems with contrasting crop rotations and external inputs. Agron J 103(1): 182-192. https://doi.org/10.2134/agronj2010.0211

Davis AS, Hill JD, Chase CA, Johanns AM, Liebman M (2012) Increasing cropping system diversity balances productivity, profitability and environmental health. PLoS ONE 7(10):e47149. https:// doi.org/10.1371/journal.pone.0047149

de Goede DM, Gremmen B, Blom-Zandstra M (2013) Robust agriculture: balancing between vulnerability and stability. Wagen J Life Sci 64(Supplement C):1-7. https://doi.org/10.1016/j.njas.2012.03.001

Elmqvist T, Folke C, Nyström M, Peterson G, Bengtsson J, Walker B, Norberg J (2003) Response diversity, ecosystem change, and resilience. Front Ecol Environ 1(9):488-494. https://doi.org/10.1890/ 1540-9295(2003)001[0488:RDECAR]2.0.CO;2 
Farhangfar S, Bannayan M, Khazaei HR, Baygi MM (2015) Vulnerability assessment of wheat and maize production affected by drought and climate change. Internat J Disast Risk Re 13:3751. https://doi.org/10.1016/j.ijdrr.2015.03.006

Fuentes M, Govaerts B, De León F, Hidalgo C, Dendooven L, Sayre KD, Etchevers J (2009) Fourteen years of applying zero and conventional tillage, crop rotation and residue management systems and its effect on physical and chemical soil quality. Eur J Agron 30(3): 228-237. https://doi.org/10.1016/j.eja.2008.10.005

Gan YT, Liang BC (2010) Ratios of carbon mass in nodules to other plant tissues in chickpea. Plant Soil 332(1-2):257-266. https://doi.org/10. 1007/s11104-010-0290-9

Gan YT, Siddique KHM, MacLeod WJ, Jayakumar P (2006) Management options for minimizing the damage by ascochyta blight (Ascochyta rabiei) in chickpea (Cicer arietinum L.). Field Crop Res 97(2-3):121-134. https://doi.org/10.1016/j.fcr.2005.10.0

Gan Y, Zentner RP, McDonald CL, Warkentin T, Vandenberg A (2009) Adaptability of chickpea in northern high latitude areas-maturity responses. Agric For Meterol 149(3-4):711-720. https://doi.org/10. 1016/j.agrformet.2008.10.026

Gan Y, Liang C, Chai Q, Lemke RL, Campbell CA, Zentner RP (2014) Improving farming practices reduces the carbon footprint of spring wheat production. Nat Commun 5:1-13. https://doi.org/10.1038/ ncomms 6012

Gan Y, Hamel C, O'Donovan JT, Cutforth H, Zentner RP, Campbell CA, Niu Y, Poppy L (2015) Diversifying crop rotations with pulses enhances system productivity. Sci Rep 5(14625):1-14. https://doi.org/ 10.1038/srep14625

Ganjeali A, Porsa H, Bagheri A (2011) Assessment of Iranian chickpea (Cicer arietinum L.) germplasms for drought tolerance. Agric Water Manag 98(9):1477-1484. https://doi.org/10.1016/j.agwat.2011.04. 017

Gaudin ACM, Tolhurst TN, Ker AP, Janovicek K, Tortora C, Martin RC, Deen W (2015) Increasing crop diversity mitigates weather variations and improves yield stability. PLoS One 10(2):e0113261. https://doi.org/10.1371/journal.pone.0113261

Gossen BD, Miller PR (2004) Survival of Ascochyta rabiei in chickpea residue on the Canadian prairies. Can J Plant Pathol 26(2):142-147. https://doi.org/10.1080/07060660409507125

Gurr GM, Wratten SD, Luna JM (2003) Multi-function agricultural biodiversity: pest management and other benefits. Basic Appl Ecol 4(2):107-116. https://doi.org/10.1078/1439-1791-00122

Harrison GW (1979) Stability under environmental stress: resistance, resilience, persistence, and variability. Am Nat 113(5):659-669. https://doi.org/10.1086/283424

Holling CS (1973) Resilience and stability of ecological systems. Annu Rev Ecol Evol 4:1-23. https://doi.org/10.1146/annurev.es.04. 110173.000245

Hossain Z, Wang X, Hamel C, Diane Knight J, Morrison MJ, Gan Y (2016) Biological nitrogen fixation by pulse crops on semiarid Canadian prairies. Can J Plant Sci 97(1):119-131. https://doi.org/ 10.1139/cjps-2016-0185

Ifejika Speranza C, Wiesmann U, Rist S (2014) An indicator framework for assessing livelihood resilience in the context of social-ecological dynamics. Glob Environ Chang 28:109-119. https://doi.org/10. 1016/j.gloenvcha.2014.06.005

Kathiresan RM (2007) Integration of elements of a farming system for sustainable weed and pest management in the tropics. Crop Prot 26(3):424-429. https://doi.org/10.1016/j.cropro.2005.11.015

Koocheki A, Nassiri M, Alimoradi L, Ghorbani R (2009) Effect of cropping systems and crop rotations on weeds. Agron Sustain Dev 29(2):401-408. https://doi.org/10.1051/agro/2008061

Kremen C, Miles A (2012) Ecosystem services in biologically diversified versus conventional farming systems: benefits, externalities, and trade-offs. Ecol Soc 17(4). https://doi.org/10.5751/ES-05035170440
Kumar V, Rawat AK, Rao DLN (2017) Population ecology of soybeanrhizobia in diverse crop rotations in Central India. Agric Ecosyst Environ 240:261-268. https://doi.org/10.1016/j.agee.2017.02.011

Leport L, Turner NC, French RJ, Barr MD, Duda R, Davies SL, Tennant D, Siddique KHM (1999) Physiological responses of chickpea genotypes to terminal drought in a Mediterranean-type environment. Eur J Agron 11(3-4):279-291. https://doi.org/10.1016/S11610301(99)00039-8

Liebman M, Helmers MJ, Schulte LA, Chase CA (2013) Using biodiversity to link agricultural productivity with environmental quality: results from three field experiments in Iowa. Agric Food Syst 28(2):115-128. https://doi.org/10.1017/S1742170512000300

Lin BB (2011) Resilience in agriculture through crop diversification: adaptive management for environmental change. BioScience 61(3):183-193. https://doi.org/10.1525/bio.2011.61.3.4

Lin BB, Perfecto I, Vandermeer J (2008) Synergies between agricultural intensification and climate change could create surprising vulnerabilities for crops. BioScience 58(9):847-854. https://doi.org/10. 1641/B580911

Liu Y, Wang EL, Yang XG, Wang J (2010) Contributions of climatic and crop varietal changes to crop production in the North China Plain, since 1980s. Glob Chang Biol 16(8):2287-2299. https://doi.org/10. $1111 / j .1365-2486.2009 .02077 . x$

Lu X, White H (2014) Robustness checks and robustness tests in applied economics. J Econ 178:194-206

Malhi S, Harapiak J, Karamanos R, Gill K, Flore N (2003) Distribution of acid extractable $\mathrm{P}$ and exchangeable $\mathrm{K}$ in a grassland soil as affected by long-term surface application of N, P and K fertilizers. Nutr Cycl Agroecosyst 67(3):265-272

McMaster GS, Wilhelm WW (1997) Growing degree-days: one equation, two interpretations. Agric For Meterol 87(4):291-300. https://doi. org/10.1016/S0168-1923(97)00027-0

Mondal S, Rutkoski JE, Velu G, Singh PK, Crespo-Herrera LA, Guzmán C, Bhavani S, Lan C, He X, Singh RP (2016) Harnessing diversity in wheat to enhance grain yield, climate resilience, disease and insect pest resistance and nutrition through conventional and modern breeding approaches. Front Plant Sci 7(991). https://doi.org/10. 3389/fpls.2016.00991

Napel Jt, Bianchi F, Bestman M (2006) Utilising intrinsic robustness in agricultural production systems: inventions for a sustainable development of agriculture. In: Inventions for a sustainable development of agriculture. Trans Forum Agro Groen, pp 32-53

Navas-Cortés JA, Trapero-Casas A, Jimẽnez-Dìaz RM (1998) Influence of relative humidity and temperature on development of Didymella rabiei on chickpea debris. Plant Pathol 47(1):57-66. https://doi.org/ 10.1046/j.1365-3059.1998.00208.x

Nichols V, Verhulst N, Cox R, Govaerts B (2015) Weed dynamics and conservation agriculture principles: a review. Field Crop Res 183: 56-68. https://doi.org/10.1016/j.fcr.2015.07.012

Olsen S, Sommers L (1982) Methods of soil analysis. Phosphorus. ASA and SSSA, Madison, WI, United States

Paolini R, Faustini F, Saccardo F, Crinò P (2006) Competitive interactions between chickpea genotypes and weeds. Weed Res 46(4):335-344. https://doi.org/10.1111/j.1365-3180.2006.00513.x

Pimm SL (1984) The complexity and stability of ecosystems. Nature 307(5949):321-326. https://doi.org/10.1038/307321a0

Reckling M, Bergkvist G, Watson CA, Stoddard FL, Zander PM, Walker RL, Pristeri A, Toncea I, Bachinger J (2016) Trade-offs between economic and environmental impacts of introducing legumes into cropping systems. Front Plant Sci 7(669). https://doi.org/10.3389/ fpls.2016.00669

Ross AM, Rhodes DH, Hastings DE (2008) Defining changeability: reconciling flexibility, adaptability, scalability, modifiability, and robustness for maintaining system lifecycle value. Syst Eng 11(3): 246-262 
Sabatier R, Wiegand K, Meyer K (2013) Production and robustness of a cacao agroecosystem: effects of two contrasting types of management strategies. PLoS One 8(12):e80352. https://doi.org/10.1371/ journal.pone. 0080352

Smirnov O, Zhang M, Xiao T, Orbell J, Lobben A, Gordon J (2016) The relative importance of climate change and population growth for exposure to future extreme droughts. Clim Chang 138(1-2):41-53. https://doi.org/10.1007/s10584-016-1716-z

Smith AN, Reberg-Horton SC, Place GT, Meijer AD, Arellano C, Mueller JP (2011) Rolled rye mulch for weed suppression in organic no-tillage soybeans. Weed Sci 59(2):224-231. https://doi.org/10. 1614/WS-D-10-00112.1

Stott P (2016) How climate change affects extreme weather events: research can increasingly determine the contribution of climate change to extreme events such as droughts. Science 352(6293):1517-1518. https://doi.org/10.1126/science.aaf7271

Tao S, Xu Y, Liu K, Pan J, Gou S (2011) Research progress in agricultural vulnerability to climate change. Adv Clim Chang Res 2(4):203-210. https://doi.org/10.3724/SP.J.1248.2011.00203
Urruty N, Tailliez-Lefebvre D, Huyghe C (2016) Stability, robustness, vulnerability and resilience of agricultural systems. A review. Agron Sustain Dev 36(1):15. https://doi.org/10.1007/s13593-0150347-5

Vallina SM, Le Quéré C (2011) Stability of complex food webs: resilience, resistance and the average interaction strength. Eur J Agron 272(1):160-173. https://doi.org/10.1016/j.jtbi.2010.11.043

Zhang J, Iwaasa AD, Han G, Gu C, Wang H, Jefferson PG, Kusler J (2018) Utilizing a multi-index decision analysis method to overall assess forage yield and quality of $\mathrm{C} 3$ grasses in the western Canadian prairies. Field Crop Res 222:12-25. https://oi.org/10. 1016/j.fcr.2018.03.007

Zhu Y, Chen H, Fan J, Wang Y, Li Y, Chen J, Fan J, Yang S, Hu L, Leung H, Mew TW, Teng PS, Wang Z, Mundt CC (2000) Genetic diversity and disease control in rice. Nature 406(6797):718-722. https://doi. org/10.1038/35021046

Publisher's note Springer Nature remains neutral with regard to jurisdictional claims in published maps and institutional affiliations. 